\title{
Comprehensive Overview of Decision-Fusion Technique in Healthcare A Scoping Review Protocol
}

\author{
Elham Nazari , 1 (i) Reza Pour ${ }^{2}$, Hamed Tabesh¹ \\ 1- Department of Medical Informatics, Faculty of Medicine, Mashhad University of Medical Sciences, Mashhad, Iran. \\ 2- Department of Computer Engineering, Islamic Azad University, Mashhad Branch, Mashhad, Iran.
}

\section{ABSTRACT}

Introduction: In recent decades, the use of Decision-Fusion techniques has attracted the attention of many scholars and academics. The use of this technique to manage challenges such as diversity and scalability in the Big Data is very common in various industries, including the health care industry. Hence, a comprehensive review of studies on the use of this technique in the field of health care and its review of the types of applied methods, the type of used data, the obtained data, the use and purpose of technique can be useful. Therefore, the protocol of this Scope Review article will be presented to examine this technique in the field of health care.

Material and Methods: The protocol was designed based on O'Malley and Arksey's five-step framework in combination with Levac and colleages' enhancement. First, a field-specific structure was defined for study. This structure consists of three main aspects: the purpose and hypothesis, modeling, model achievements. Considering this structure, the 5-step framework was created for the study. Three databases, PubMed, science direct, and EMBASE were selected for search and an appropriate strategy for incorporating health related articles that utilized this technique was used. Data was extracted based on defined aspects, and categories were created based on their frequency. To analyze the extracted data from articles, frequency analysis, descriptive statistical methods and qualitative thematic analysis will be used.

Results: This paper is the first study of Scope Review regarding the use of Decision-Fusion technology in health care. Reference frame questions aspects are designed as field-specific. To clarify the research questions, O'Malley Arksey's five-step framework was used in combination with Levac et al.enhancement. A classify scheme for the category of the aspects [for the categorization of the dimensions] was presented based on the frequency of their values.

Conclusion: A classify scheme for the category of the aspects [for the categorization of the dimensions] was presented based on the frequency of their values.

(i) Please cite this article as:

Nazari E, Pour R, Tabesh H. Comprehensive Overview of Decision-Fusion Technique in Healthcare: A Scoping Review Protocol. Iran J Med Inform. 2018; 7(1): e7. DOI: $\underline{10.24200 / i j m i . v 7 i 0.164}$
Article History

Received: 2018-11-04

Accepted: 2018-11-19

Published: 2018-11-28

\section{Keywords}

Decision fusion

Decision making

Health care

Medicine

\footnotetext{
* Corresponding Author: H Tabesh, Department of Medical Informatics, Faculty of Medicine, Mashhad University of Medical Sciences, Mashhad, Iran. (Email: tabeshh@mums.ac.ir) 


\section{INTRODUCTION}

In recent decades, the information fusion techniques has become the hot topic, because today, conventional and traditional methods are not responsive for data management and analysis. The reason for this is the fact that in addition to producing a large amount of data in all industries, including in the healthcare industry, these types of data, known as Big Data, face challenges such as diversity, scalability and complexity. To manage these challenges, using Decision-Fusion techniques will be helpful in order to be able to manage this type of healthcare data correctly in improving prevention, early diagnosis, treatment, rehabilitation, monitoring [1]. By using this technique in the field of health care, care costs will be reduced, quality of care will be improved and the ability to share information will be provided for easy use by care professionals. So, there are a lot of demands for using this technique in various health care sectors and aspects $[1,2]$. This technique was introduced for sensor applications and military affairs in the 1960s []ㅡ.

The technique addresses all aspects of the combination of information from different sources for making decision. In fact, its goal is to select the most suitable features, reduce complexity to an analytic-manageable level, optimize and summarize information [ [4-6] ] transform information into a form with easy and comprehensive management and it is used to increase the accuracy and provide results without bias [7].

Many studies have been conducted in various areas, including sensor area, image processing, pattern recognition in healthcare and etc. The results of studies indicate the great benefits of this technique in data management with the stated conditions [8]. The most important point in using this technique is knowing the problem space, such as data type and its effective factors, and selecting the appropriate method for its management and analysis $[\underline{5}, 6]$. On the other hand, as Scoping review studies provide a rich source of knowledge and evidence for future studies, a comprehensive scope review is needed for better understanding of researchers in using Decision-Fusion in health care [9].

According to our knowledge, there is no scope review study in this regard; so, this type of study has been considered. Performing of scope review takes a lot of time and it is hard to do. An initial protocol will provide a map of the scoping review study and will prevent the problems during the study [10]. This article will describe the details of a protocol article.

\section{MATERIAL AND METHODS}

The protocol of this study is based on the Arksey and O'Malley's framework that is one of the first designed methodological and commonly frameworks to design a scoping review [11]. The scope review is an evidence-based article that answered a range of research questions and provides directions for future research for advance healthcare practice, policy and research. This valuable study faces challenges such as variability and lack of consensus in scoping review terminology, definition, methodological conduct, and reporting. So, for clarity, the terms, definitions, and methods of the Arksey and O'Malley's framework were used in combination with Levac et al. enhancement [9]. The Arksey and O'Malley framework consists of 5 main stages and an optional stage and in the present study, recommendations are presented in combination with Levac et al. enhancement to clarify each stage. The 5 major stages of Arksey and O'Malley's framework and its optional stage include:
Stage1. The identification of a research question,

Stage2. The identification of studies relevant to the research question,

Stage3. A selection of studies for inclusion in its review,

Stage 4. The charting of information and data within the included studies and

Stage5. Collecting, summarizing and reporting the results

Stage6. Consultation [optional] [11].

In this study, a field-specific structure has been defined on the basis of studies. This structure consisted of three main aspects: Purpose and hypothesis, modeling, model achievements. Considering this structure, subsequently, the 5th stages of Arksey and O'Malley's framework have been responded. In this study, the optional stage 6 was not used. This stage provides opportunities for the client and the involved stakeholders to offer additional references and to go beyond literature $[9,11]$.

\section{Stage 1: Identifying the research question}

There are wide-ranging questions in scoping review, because this type of study emphasizes the summary of evidence in all its aspects. Questions for the next stage are as guidance. Therefore, the main aspects for defining the questions are defined initially which are listed in Table 1:

Table 1: Questions of research

\begin{tabular}{|l|l|}
\hline Aspect & List of questions \\
\hline \multirow{5}{*}{ General } & In what years were studies published? \\
\cline { 2 - 3 } $\begin{array}{l}\text { In which countries were studies } \\
\text { conducted? }\end{array}$ \\
\cline { 2 - 2 } $\begin{array}{l}\text { Wurpose } \\
\text { hypothesis } \\
\text { the studies? }\end{array}$ \\
\hline Modeling & $\begin{array}{l}\text { For what field of health care, this study } \\
\text { was designed? }\end{array}$ \\
\cline { 2 - 2 } & $\begin{array}{l}\text { For what target population of health care } \\
\text { [level of health promotion] this study was } \\
\text { designed? }\end{array}$ \\
\cline { 2 - 2 } & What was the purpose of the study? \\
\hline & $\begin{array}{l}\text { What methods have been used in this } \\
\text { study? }\end{array}$ \\
\cline { 2 - 2 } & $\begin{array}{l}\text { What type of data set was selected in this } \\
\text { study? }\end{array}$ \\
\cline { 2 - 2 } & $\begin{array}{l}\text { What software was selected to implement } \\
\text { and conduct this study? }\end{array}$ \\
\hline Model Achievement & $\begin{array}{l}\text { What was the purpose of the result of this } \\
\text { study? }\end{array}$ \\
\hline
\end{tabular}

Based on the Levac et al. enhancement model, some recommendations are presented in Table 2 for clarifying stage one [9].

Table 2: Recommended items in the Levac et al. enhancement framework

\begin{tabular}{|l|l|}
\hline $\begin{array}{l}\text { Recommend } \\
\text { item }\end{array}$ & Description in current study \\
\hline Concept & $\begin{array}{l}\text { Decision-Fusion techniques in health } \\
\text { care field }\end{array}$ \\
\hline $\begin{array}{l}\text { Target } \\
\text { population }\end{array}$ & $\begin{array}{l}\text { All data sets that have been used in } \\
\text { some kind of Decision-Fusion technique } \\
\text { in their research. }\end{array}$ \\
\hline Purpose & $\begin{array}{l}\text { Identification of Decision-Fusion } \\
\text { techniques used in health care field. }\end{array}$ \\
\hline Output & A list of suggested recommendation \\
\hline
\end{tabular}




\section{Stage 2: Identifying relevant studies}

At this stage, the research strategy is described including research basis, terminology, time period for research and the language of the search. So, our search was done in PubMed, Science Direct, and EMBASE databases. Used Databases are well known in healthcare and/or has covered a lot of articles related this technique [12]. A number of key words related to the core concept were recommended and approved by the research team after reviewing the texts and used to determine the strategy as seen in the Table 3. Published papers from 1960 to 2017 were reviewed because this technique was introduced by the US Department of Defense in 1960 to collect data from and most of its applications have been restricted to sensor area, for many years [] $]$ and the language of the articles was limited to English.

Table 3: Related keywords

\begin{tabular}{|l|l|}
\hline Concept & Synonym \\
\hline Decision-Fusion & Information fusion \\
\cline { 2 - 2 } & symbolic fusion \\
\cline { 2 - 2 } & Sensor fusion \\
\cline { 2 - 2 } & Expert fusion \\
\cline { 2 - 2 } & distributed decision \\
\hline Heaths care & Med* \\
\hline
\end{tabular}

The summary of the research process is illustrated in Fig 1:

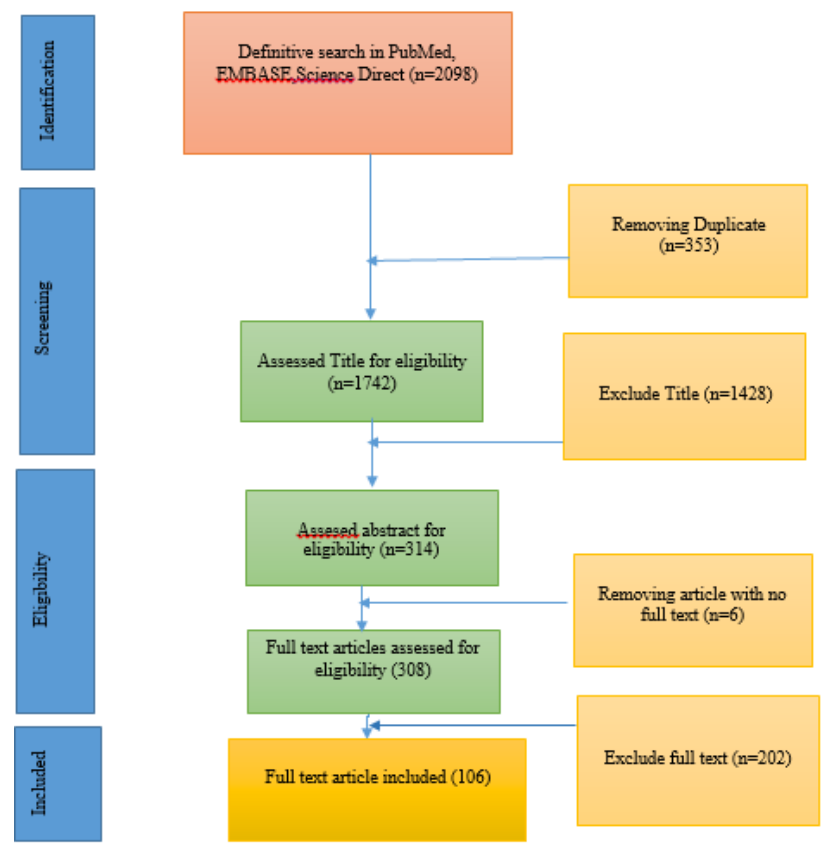

Fig 1: Summary of research process

\section{Stage 3: Study selection}

Inclusion criteria of the study include the following:

Research or study has used at least one Decision-Fusion technique.

The goal of the study should be in one of the health care fields.

Exclusion criteria include articles from the following types:

non-original

research materials like review studies

Studies describing theoretical concepts or proposing frameworks.
Specialist's commentaries and editorials.

According to the inclusion and exclusion criteria separately, two researchers reviewed the title and abstract to separate related articles to the purpose of the study. After confirming the relevance, the full texts were examined those two researchers. In case of a discrepancy, this problem will be solved by consulting the third researcher. Fig 2 shows a summary of stage 3:

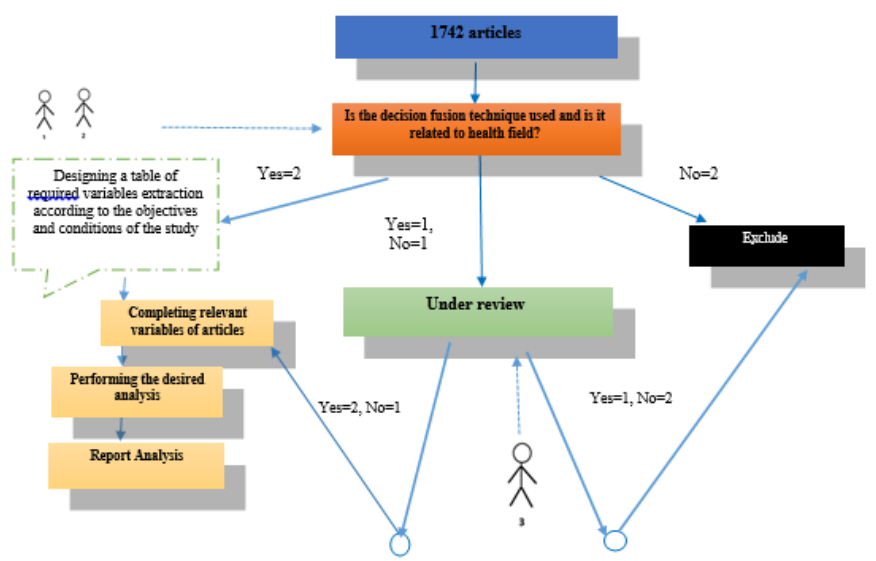

Fig 2: Summary of research process

Stage 4. Charting the data

The stage of suitable variables with research questions will be extracted. We have a variable and a permitted value for each variable. These variables are listed in Table 4.

At this stage, the reviewers extract the data in a duplicate process and update the charting form. The reviewers chart the forms in pilot design on 5 to 10 studies to determine whether their approach is consistent with the research question and purpose for extracting the data.

\section{Stage 5: Collecting, summarizing and reporting the results}

Data extraction is done in a table in Excel that each row represents an article and the columns represent the desired variables and the value of each row in the column [cell] contains the variable value. The data were extracted and categories were created based on their frequency for them. In order to ensure the proper classification, the two validity and reliability indexes were checked to evaluate the classification validity by 5 field experts' comments. To assess reliability, numbers of articles were randomly selected and assigned to two reviewers to extract the items from articles. The Kappa statistic was used to check those two reviewers' agreements. And after calculating, $84 \%$ of agreement was obtained to ensure that the reviewers have the same interpretation of the data and categories. After this stage, the extraction of information from all the final papers will be started to review.

For analyzing the data table frequency analysis, descriptive statistics and qualitative thematic analysis will be used. After the analysis, the results will be reported either graphically or in the form of a table. Then, the related findings to the study's purpose will be discussed and for future studies, some recommends will be suggested. 
Table 4: List of studied variables from articles

\begin{tabular}{|c|c|c|}
\hline Aspect & Variables & Permitted value \\
\hline \multirow[t]{3}{*}{$\begin{array}{l}\text { General } \\
\text { information }\end{array}$} & $\begin{array}{l}\text { Publication } \\
\text { year }\end{array}$ & $1960-2017$ \\
\hline & $\begin{array}{l}\text { Geographical } \\
\text { location } \\
\text { [country] }\end{array}$ & All country \\
\hline & $\begin{array}{l}\text { Author's } \\
\text { discipline }\end{array}$ & All discipline \\
\hline \multirow[t]{3}{*}{$\begin{array}{l}\text { Purpose and } \\
\text { hypothesis }\end{array}$} & Area & $\begin{array}{l}\text { Imageprocessing,sensor, } \\
\text { diagnosis,biology } \\
\text {,signalprocessing,health } \\
\text { sinformtics }\end{array}$ \\
\hline & $\begin{array}{l}\text { Level of health } \\
\text { promotion }\end{array}$ & $\begin{array}{l}\text { Prevention } \\
\text { Diagnosis } \\
\text { Treatment and } \\
\text { rehabilitation }\end{array}$ \\
\hline & Objective study & $\begin{array}{l}\text { Improve } \\
\text { diagnosis,detect new } \\
\text { treatment and etc }\end{array}$ \\
\hline \multirow[t]{3}{*}{ Modeling } & Methods & $\begin{array}{l}\text { Beysian,fuzzy, neural } \\
\text { network, Dempster- } \\
\text { Shafer theory and etc }\end{array}$ \\
\hline & type of dataset & $\begin{array}{l}\text { research project } \\
\text { data,online } \\
\text { dataset,simulation }\end{array}$ \\
\hline & Software & $\begin{array}{l}\text { Mathlab,c++,c\#, weka } \\
\text { and etc }\end{array}$ \\
\hline $\begin{array}{l}\text { Model } \\
\text { Achievement }\end{array}$ & Result & $\begin{array}{l}\text { Increase } \\
\text { accuracy,precision and } \\
\text { etc }\end{array}$ \\
\hline
\end{tabular}

\section{RESULTS}

According to our knowledge, there are no review scopes in this field and goal. In this study, a protocol was used for doing a review scope on using Decision-Fusion Techniques in Health Care Fields by Using the Arksey and O'Malley Framework in Combination with Levac et al. enhancement. A classify scheme was proposed for classification based on the frequency of values. The results of the analysis will help researchers by a summary of evidence to present new ideas and further research.

\section{REFERENCES}

1. Zhong H, Xiao J. Enhancing health risk prediction with deep learning on big data and revised fusion node paradigm. Scientific Programming. 2017; 2017:1-18.

2. Mayer MA, Heinrich A, Rodríguez A, Sasaki F, Xu F, Garattini C. Big data technologies in healthcare: Needs, opportunities and challenges. Big Data Value Association. 2016.

3. Balazs JA, Velásquez JD. Opinion mining and information fusion: A survey. Information Fusion. 2016; 27: 95-110.

4. Gu Y, Yang M, Shi Z, Wu Z. The applications of decision-level data fusion techniques in the field of multiuser detection for DS-UWB systems. Sensors. 2015; 15(10):24771-90. PMID: 26404273 DOI: $10.3390 / \mathrm{s} 151024771$ [PubMed]

5. Bossé É, Roy J, Wark S. Concepts, models, and tools for information fusion. Artech House; USA. 2007.

6. Torra V. Information fusion in data mining. Springer; USA. 2009.

7. Mangai UG Samanta S, Das S, Chowdhury PR. A survey of decision fusion and feature fusion strategies for pattern classification. IETE Technical Review. 2010; 27(4): 293-307.

8. Bossae A, Solaiman B. Information fusion and analytics for big data and IoT. Artech House; USA. 2016.

9. Colquhoun HL, Levac D, O'Brien KK, Straus S, Tricco AC, Perrier L, et al. Scoping reviews: Time for clarity in definition, methods, and reporting. J Clin Epidemiol. 2014; 67(12): 1291-4. PMID:25034198 DOI: 10.1016/j.jclinepi.2014.03.013 [ PubMed]

10. Tricco AC, Lillie E, Zarin W, O'Brien K, Colquhoun H, Kastner $\mathrm{M}$, et al. A scoping review on the conduct and reporting of scoping reviews. BMC Med Res Methodol. 2016; 16(1): 1525. PMID: 26857112 DOI: 10.1186/s12874-016-0116-4 [PubMed]

11. Khalil H, Peters M, Godfrey CM, McInerney P, Soares CB, Parker D. An evidence-based approach to scoping reviews. Worldviews Evid Based Nurs. 2016; 13(2): 118-23. PMID: 26821833 DOI: 10.1111/wvn.12144 [PubMed]

12. Bramer WM, Rethlefsen ML, Kleijnen J, Franco OH. Optimal database combinations for literature searches in systematic reviews: A prospective exploratory study. Syst Rev. 2017; 6(1): 245-57. PMID: 29208034 DOI: 10.1186/s13643-0170644-y [PubMed]

\section{CONCLUSION}

This study examines the studies related to use of techniques in the field of health .The results of this scope review provide a comprehensive view of the Decision-Fusion technique in the field of health care and helps researchers choose the right methods in future research. All data was extracted from general resources and articles and thus, this study does not require moral confirmation. We anticipate that this study could be a reference for using Decision-Fusion in the field of health care and the source of new ideas for future studies. 